\title{
ANALYSIS OF A CHEMICALLY REACTIVE MHD FLOW WITH HEAT AND MASS TRANSFER OVER A PERMEABLE SURFACE
}

\author{
O.J. FENUGA* and S.J. AROLOYE \\ Department of Mathematics, University of Lagos \\ NIGERIA \\ E-mails: ofenuga@unilag.edu.ng; fenuga_oj@yahoo.co.uk; saroloye@unilag.edu.ng \\ A.O. POPOOLA \\ Osun State University \\ Osogbo, NIGERIA \\ E-mail: amos.popoola@uniosun.edu.ng
}

\begin{abstract}
This paper investigates a chemically reactive Magnetohydrodynamics fluid flow with heat and mass transfer over a permeable surface taking into consideration the buoyancy force, injection/suction, heat source/sink and thermal radiation. The governing momentum, energy and concentration balance equations are transformed into a set of ordinary differential equations by method of similarity transformation and solved numerically by RungeKutta method based on Shooting technique. The influence of various pertinent parameters on the velocity, temperature, concentration fields are discussed graphically. Comparison of this work with previously published works on special cases of the problem was carried out and the results are in excellent agreement. Results also show that the thermo physical parameters in the momentum boundary layer equations increase the skin friction coefficient but decrease the momentum boundary layer. Fluid suction/injection and Prandtl number increase the rate of heat transfer. The order of chemical reaction is quite significant and there is a faster rate of mass transfer when the reaction rate and Schmidt number are increased.
\end{abstract}

Key words: heat and mass transfer, chemically reactive MHD flow, permeable surface .

\section{Introduction}

The hydromagnetic flow and heat transfer over a surface have practical, industrial and engineering applications in the streamlined expulsion of plastic sheets, paper creation, glass blowing, metal turning, drawing plastic film, aerodynamic expulsion of plastic sheets, condensation process of metallic plate in the cooling bath and expulsion of a polymer sheet from a colour. Chamkha [1] solved a general boundary layer problem governing steady, Laminar, hydromagnetic flow with heat and mass transfer over a permeable cylinder moving with a linear velocity in the presence of heat/absorption, chemical reation, suction/injection effects and uniform transverse magnetic field using standard, fully implicit, iterative, tri-diagonal finite difference method. Aziz [2] obtained a similarity solution for a Laminar boundary layer flow over a flat plate with a convective surface boundary condition. Bhattacharyya and Gorla [3] solved the axisymmetric boundary layer flow and heat transfer past a permeable shrinking cylinder subject to surface mass transfer using finite difference method of quasilimearization technique. Bhattacharyya and Layek [4] analyzed the distribution of a reactant solute undergoing first order chemical reaction in the boundary layer flow of an electrically conducting incompressible fluid over a permeable stretching sheet subjected to suction or blowing using finite difference method of quasilinearization technique. Also, Bhattacharyya [5], considered

\footnotetext{
* To whom correspondence should be addressed
} 
the effects of heat source /sink on the steady two dimensional MHD boundary layer flow and heat transfer past shrinking sheet with wall mass suction using finite difference method of quasilinearization technique. Arthur et al. [6] investigated the hydromagnetic flow over a flat surface with convective boundary condition and internal heat generation in the presence of chemical reaction using Newton-Raphson Shooting method along with fourth order Runge-Kutta algorithm. Gnaneswara and Sandeep [7] analyzed the heat and mass transfer in Carreau fluid flow over a permeable stretching sheet with convective slip condition in the presence of applied magnetic field, nonlinear thermal radiation, cross diffusion and suction/injection effects using Runge-Kutta and Newton's method. Also, Nayak [8] considered a steady MHD flow of a viscous conducting fluid past a stretched permeable vertical permeable surface with heat generation/absorption, thermal radiation and chemical reaction using Runge- Kutta method based on Shooting technique. Prakash et al. [9] examined the hydromagnetic two dimensional boundary layer flow of a non-Newtonian fluid accompanied by heat and mass transfer towards an exponentially stretching sheet in the presence of chemical reaction and thermal radiation using Casson model. Sulochana and Kishor Kumar [10] used shooting technique to analyze the heat and mass transfer in magnetohydrodynamic flow over a stretching sheet in the presence of thermal radiation and chemical reaction. Seth et al. [11] used exact solution in closed form and numerical solution to investigate an unsteady hydrodynamic natural convection flow with heat and mass transfer of a viscous incompressible, electrically conducting, chemically reactive and optically thin radiating fluid past an exponentially accelerated moving vertical plate with arbitrary ramped temperature, embedded in a fluid saturated in a porous medium. Also, Hayat et al. [12] obtained convergent series solutions for a boundary layer flow of a Nano fluid over power-law stretched surface in the presence of applied magnetic field and chemical reaction with heat and mass convective conditions. Ishak [13] provided a similarity solution for a steady, Laminar, boundary layer flow and heat transfer over a permeable flat plate in a uniform free stream with the surface of the plate heated by convection from a hot fluid. Also, Makinde and Olanrewaju [14] analyzed the effects of thermal buoyancy on the Laminar boundary layer about a vertical plate in a uniform stream of fluid under a convective surface boundary condition using fourth order RungeKutta iteration scheme. Olanrewaju et al. [15] used Shooting iteration technique with sixth order RungeKutta integration scheme to analyze the effects of internal heat generation, thermal radiation and buoyancy force on the Laminar boundary layer flow about a vertical plate in a uniform stream of fluid under a convective surface boundary condition

This work extends the work of Aziz [2], Arthur et al. [6], Ishak [13], Makinde and Olanrewaju [14] and Olanrewaju et al. [15] to include buoyancy force and fluid injection or suction on heat and mass transfer over a permeable surface of a chemically reactive magnetohydrodynamics fluid flow in the presence of heat source and sink and thermal radiation.

\section{Formulation of the problem}

Consider a steady, two dimensional boundary layer flow of a stream of cold, incompressible, electrically conducting viscous fluid, coupled with heat and mass transfer past a permeable stretching surface. The flow is assumed to be in the direction of $x$-axis along the plate and $y$-axis is normal to the plate. A uniform magnetic field $B_{0}$ is applied in transverse direction to the flow. The left surface is heated by convection from a hot fluid at temperature $T_{f}$ which provides a heat transfer coefficient $h_{f}$. Also, the left surface of the plate is heated by convection from a viscous fluid at concentration $c_{f}$ to give rise to a coefficient mass transfer and the right side of the plate is electrically conducting 


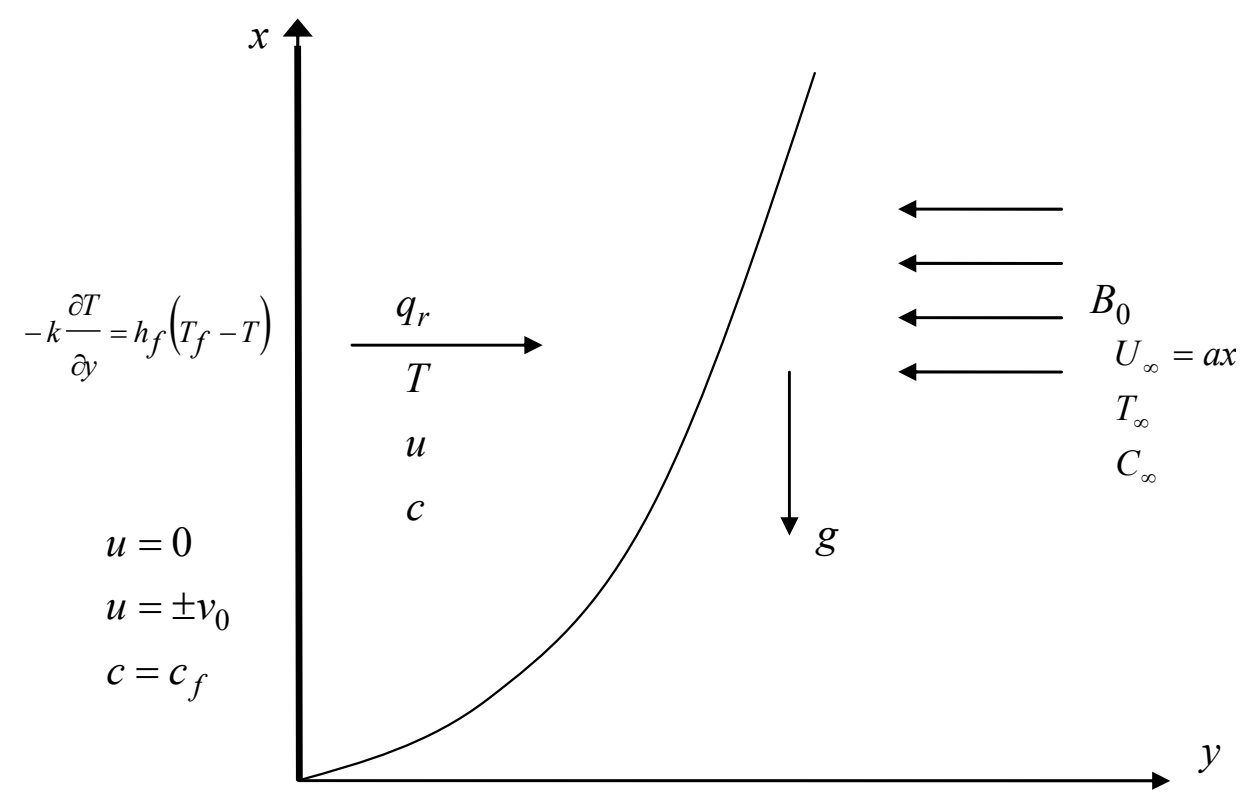

Fig.1. Flow configuration and coordinate system.

The governing continuity, momentum, energy and concentration equations are

$$
\begin{aligned}
& \frac{\partial u}{\partial x}+\frac{\partial v}{\partial y}=0 \\
& u \frac{\partial u}{\partial x}+v \frac{\partial u}{\partial y}=\gamma \frac{\partial^{2} u}{\partial y^{2}}+g \beta\left(T-T_{\infty}\right)-\frac{\sigma B_{0}^{2}\left(u-U_{\infty}\right)}{\rho}-\frac{\gamma}{\kappa_{p}}\left(u-U_{\infty}\right) \\
& u \frac{\partial T}{\partial x}+v \frac{\partial T}{\partial y}=\frac{K}{\rho C_{p}} \frac{\partial^{2} T}{\partial y^{2}}+\frac{\gamma}{C_{p}}\left(\frac{\partial u}{\partial y}\right)^{2}+\frac{\sigma B_{0}^{2}\left(u-U_{\infty}\right)^{2}}{\rho C_{p}}+\frac{Q}{\rho C_{p}}\left(T-T_{\infty}\right)-\frac{1}{C_{p}} \frac{\partial q_{r}}{\partial y} \\
& u \frac{\partial C}{\partial x}+v \frac{\partial C}{\partial y}=D_{m} \frac{\partial^{2} C}{\partial y^{2}}-K_{r}\left(C-C_{\infty}\right)^{n}
\end{aligned}
$$

where $u, v, T, C$ are respectively the $x$ and $y$.components of the velocity; temperature and concentration components while $U_{\infty}, T_{\infty}$ and $C_{\infty}$ are respectively the velocity, temperature and concentration outside the plate, $\gamma$ is the coefficient of kinematic viscosity, $\beta$ is the thermal expansion coefficient, $\sigma$ is the electrical conductivity, $g$ is the acceleration due to gravity, $\rho$ the density, $C_{p}$ the specific heat at constant pressure, $K$ the thermal conductivity, $B_{0}$ is the magnetic strength, $D_{m}$ is the mass diffusivity, $K_{r}$ is the reaction rate constant, $n$ is the order of the chemical reaction and $q_{r}$ is the radiative heat flux.

The corresponding boundary conditions are

$$
u(x, 0)=0, \quad v(x, 0)= \pm V_{0}, \quad-k \frac{\partial T}{\partial y}(x, 0)=h_{f}\left(T_{f}-T(x, 0)\right), \quad C(x, 0)=C_{f},
$$




$$
u(x, \infty)=U_{\infty}=a x, \quad T(x, \infty)=T_{\infty}, \quad C(x, \infty)=C_{\infty}
$$

where $a$ is a constant. Using Rosseland approximation, the radiative heat flux $q_{r}$ is given by

$$
q_{r}=-\frac{4 \sigma^{*}}{3 K^{\prime}} \frac{\partial T^{4}}{\partial y}
$$

where $\sigma^{*}$ and $K$ are the Stefan-Boltzmann constant and the mean absorption coefficient respectively.

Assuming that the temperature differences within the flow are sufficiently small, then, Eq.(2.7) can be linearized by expanding $T^{4}$ in Taylor series about the free stream temperature $T_{\infty}$ and neglecting higherorder terms to obtain

$$
T^{4} \approx 4 T_{\infty}^{3} T-3 T_{\infty}^{4}
$$

Then substituting Eqs (2.8) in (2.7) gives

$$
q_{r}=-\frac{16 T_{\infty}^{3} \sigma^{*}}{3 K} \frac{\partial^{2} T^{4}}{\partial y^{2}}
$$

Using the similarity transformation

$$
\eta=x^{\frac{1}{2}} y \sqrt{\frac{u_{e}}{\gamma}}, u=U_{\infty} f^{\prime}, \quad v=\frac{1}{2} \sqrt{\frac{U_{\infty}}{x}} \gamma\left(\eta f^{\prime}-f\right), \theta(\eta)=\frac{T-T_{\infty}}{T_{f}-T_{\infty}}, c(\eta)=\frac{C-C_{\infty}}{C_{f}-C_{\infty}} .
$$

Equation (2.1) is satisfied if we define the stream function $\psi$ as

$$
u=\frac{\partial \psi}{\partial y} \quad \text { and } \quad v=-\frac{\partial \psi}{\partial x}
$$

The governing Eqs (2.2) to (2.4) are transformed into the following ordinary differential equations

$$
\begin{aligned}
& f^{\prime \prime \prime}+\frac{1}{2} f f^{\prime \prime}+\operatorname{Gr}_{x} \theta+\left(\left(M_{x}+D a_{x}\right)-\left(1-f^{\prime}\right)\right)=0, \\
& \left(1+\frac{4}{3} \operatorname{Ra}\right) \theta^{\prime \prime}+\operatorname{Br}\left(f^{\prime \prime}\right)^{2}+\operatorname{Br} M\left(1-f^{\prime}\right)^{2}+\frac{1}{2} \operatorname{Pr} f \theta^{\prime}+\operatorname{Pr} \lambda_{x} \theta=0, \\
& \phi^{\prime \prime}+\frac{1}{2} \operatorname{Sc} f \phi^{\prime}-\operatorname{Sc} B_{x} \phi^{n}=0 .
\end{aligned}
$$

The corresponding boundary conditions take the form

$$
\begin{array}{ll}
f^{\prime}(0)=0, & f(0)=F_{w x}, \quad-\theta^{\prime}(0)=B i_{x}(1-\theta(0)), \quad \phi(0)=1, \\
f^{\prime}(\infty)=1, \quad \theta(\infty)=0, \quad \phi(\infty)=0
\end{array}
$$


where the prime symbol represents the derivative with respect to $\eta$.

For the momentum, energy and concentration equations to have similarity solutions, the parameters $G r_{x}, B_{x}, M_{x}, D a_{x}, \lambda_{x}$ must be made constants.

\section{Numerical method for solution}

The governing equations and the boundary conditions are solved using Runge-Kuttamethod based on sixth order Shooting technique.

\subsection{Particular cases}

1. For a chemical reaction of first order when $n=1$ and in the absence of buoyancy force and heat source/sink i.e., when $\mathrm{Gr}=\lambda=F_{w}=0$, then the results of this paper is the same as Arthur et al. [6].

2. For a fluid which is not chemically reactive in the absence of the magnetic field, i.e. when, $\mathrm{Sc}=K=M=\mathrm{Br}=F_{w}=0$ then the result of this paper will be same as Olanrewaju et al. [15].

3. In the absence of heat source/sink, buoyancy force, radiation effects and magnetic field for a nonchemically reactive fluid i.e., when $\lambda=\mathrm{Gr}=\mathrm{Ra}=M=F_{w}=\mathrm{Sc}=K=\mathrm{Br}=0$, then the result of this paper will be same as Makinde and Olanrewaju [14], Aziz [2] and Ishak [13].

\section{Results and discussion}

Numerical calculations have been carried out for different values of thermo physical parameters controlling the fluid dynamics in the flow region. Table 1 shows the comparison of Arthur et al. [6] with the present work for the numerical values of skin friction coefficient $f^{\prime \prime}(0)$, local Nusselt number $-\theta^{\prime}(0)$ together with Sherwood number $-\phi^{\prime}(0)$ and there was a perfect agreement of result in the absence local Grashof number Gr, internal heat generation $\lambda$ and injection/suction $F_{w}$ i.e. for $\mathrm{Gr}=\lambda=F_{w}=0$. Table 2 shows the comparison of Olanrewaju et al. [15] with the present work for the numerical values of skin friction coefficient $f^{\prime \prime}(0)$, local Nusselt number $-\theta^{\prime}(0)$ together with plate surface temperature $\theta(0)$ and there was a perfect agreement of result when $\mathrm{Sc}=K=M=\mathrm{Br}=F_{w}=0$. Table 3 shows the comparison of the present work with the work of Makinde and Olanrewaju [14], Aziz [2] and Ishak [13] for numerical values of $-\theta^{\prime}(0)$ and $\theta(0)$ and there was a perfect agreement of result when $\lambda=\mathrm{Gr}=\mathrm{Ra}=M=\mathrm{Sc}=K=\mathrm{Br}=F_{w}=0$ and $\operatorname{Pr}=0.72$.

Table 1. Computations showing comparison of the Emmanuel Maurice Arthur et al. [6] for $\boldsymbol{n}=1$, $\mathrm{Gr}=\lambda=\boldsymbol{F}_{\boldsymbol{w}}=0$ and the present work.

\begin{tabular}{|l|c|c|c|c|c|c|c|c|c|c|c|c|}
\hline \multicolumn{19}{|c|}{ Arthur et al. $[6]$} & \multicolumn{3}{l|}{ Present paper } \\
\hline $\operatorname{Pr}$ & $\mathrm{Sc}$ & $M$ & $\mathrm{Ra}$ & $\mathrm{Br}$ & $K$ & $\mathrm{Bi}$ & $f^{\prime \prime}(0)$ & $-\theta^{\prime}(0)$ & $-\phi^{\prime}(0)$ & $f^{\prime \prime}(0)$ & $-\theta^{\prime}(0)$ & $-\phi^{\prime}(0)$ \\
\hline 0.72 & 0.24 & 0.1 & 0.1 & 0.1 & 0.1 & 0.1 & 0.451835 & 0.068283 & 0.248586 & 0.4518350 & 0.0682832 & 0.2485861 \\
\hline 0.72 & 0.24 & 0.1 & 0.1 & 0.1 & 0.1 & 0.1 & 0.451835 & 0.068415 & 0.494321 & 0.4518350 & 0.0684153 & 0.4943214 \\
\hline 0.72 & $0.2 i$ & 0.1 & 0.1 & 0.1 & 0.1 & 0.1 & 0.770792 & 0.064224 & 0.261862 & 0.7707922 & 0.0642241 & 0.2618619 \\
\hline 0.72 & 0.24 & 0.1 & 0.1 & 0.1 & 0.1 & 0.1 & 0.451835 & 0.066984 & 0.248586 & 0.4518350 & 0.0669838 & 0.2485861 \\
\hline 0.72 & 0.24 & 0.1 & 0.1 & 0.5 & 0.1 & 0.1 & 0.451835 & 0.042658 & 0.248586 & 0.4518350 & 0.0426580 & 0.2485861 \\
\hline
\end{tabular}


Table 2. Computations showing comparison of the Olanrewaju et al. [15] for $n=1$, $\mathrm{Sc}=K=M=\mathrm{Br}=F_{w}=0$ with the present work.

\begin{tabular}{|l|l|l|l|l|l|l|l|l|l|l|}
\hline \multicolumn{9}{|c|}{ Olanrewaju et al. $[14]$} & \multicolumn{2}{l|}{ Present paper } \\
\hline $\mathrm{Bi}$ & $\mathrm{Gr}$ & $\operatorname{Pr}$ & $\lambda$ & $\mathrm{Ra}$ & $f^{\prime \prime}(0)$ & $-\theta^{\prime}(0)$ & $\theta(0)$ & $f^{\prime \prime}(0)$ & $-\theta^{\prime}(0)$ & $\theta(0)$ \\
\hline 0.1 & 0.1 & 0.72 & 0.1 & 0.1 & 0.386316 & 0.066810 & 0.331810 & 0.38694698 & 0.066661 & 0.333390 \\
\hline 10 & 0.1 & 0.1 & 0.1 & 0.1 & 0.483261 & 0.213880 & 0.978610 & 0.48431420 & 0.212285 & 0.978771 \\
\hline 0.1 & 0.5 & 0.1 & 0.1 & 0.1 & 0.557241 & 0.069730 & 0.302690 & 0.55978647 & 0.069577 & 0.304227 \\
\hline 0.1 & 0.1 & 0.1 & 0.6 & 0.1 & 0.298365 & 0.102052 & -0.020520 & 0.29716417 & 0.102356 & -0.023564 \\
\hline
\end{tabular}

Table 3. Computations showing comparison of Makinde and Olanrewaju [14], Aziz [2] and Ishak [13] for $\lambda=\mathrm{Gr}=\mathrm{Ra}=M=\mathrm{Sc}=K=\mathrm{Br}=F_{w}=0$ and $\mathrm{Pr}=0.72$ with the present work.

\begin{tabular}{|l|l|l|l|l|l|l|}
\hline \multicolumn{2}{|c|}{ Aziz [2] } & Ishak [13] & Makinde and Olanrewaju [14] & \multicolumn{2}{l|}{ Present paper } \\
\hline $\mathrm{Bi}$ & $-\theta^{\prime}(0)$ & $\theta(0)$ & $-\theta^{\prime}(0)$ & $-\theta^{\prime}(0)$ & $-\theta^{\prime}(0)$ & $\theta(0)$ \\
\hline 0.05 & 0.0428 & 0.1447 & 0.042767 & 0.0428 & 0.0428 & 0.1447 \\
\hline 0.10 & 0.0747 & 0.2528 & 0.074724 & 0.0747 & 0.0747 & 0.2528 \\
\hline 1.00 & 0.2282 & 0.7718 & 0.228178 & 0.2282 & 0.2283 & 0.7718 \\
\hline 5.00 & 0.2791 & 0.9441 & 0.279131 & 0.2791 & 0.2791 & 0.9442 \\
\hline
\end{tabular}

Figures 2-17, together with Tabs 4, 5 and 6 shows the computational results showing the effects of various thermophysical parameters on the electrically conducting and $n t h$ order homogeneous reacting fluid velocity, temperature, concentration as well as skin-friction coefficient, plate temperature, rate of heat and mass transfer over the vertical plate. It was observed from Tab.4 that with more injection of the chemically reactive and electrically conducting fluid into the flow system, there was a corresponding rise in the skinfriction coefficient. The same result was observed by increasing the values of the magnetic parameter, Brinkman and Grashof numbers. In Tab.5, the varying values of the reaction rate parameter increased the rate of mass transfer within the flow system. On the other hand, when the order of the chemical reaction was increased, there was a retardation of the rate of mass transfer. Table 6 shows the computation of the values of plate temperature and the Nusselt number for various values of the thermo physical parameters and for a first order chemical reaction with variations in $\mathrm{Ra}, M, \mathrm{Bi}, \mathrm{Pr}, \lambda$ and $\mathrm{Br}$. Some of the parameters like $\mathrm{Ra}, \mathrm{Bi}, \lambda, M$ and $\mathrm{Br}$ increased the plate temperature while $F_{w}$ and $\mathrm{Pr}$ decreased the plate temperature. The rate at which heat is transferred, $-\theta^{\prime}(0)$ was increased by increasing the values of the Prandtl and Biot numbers as a result of convective heat exchange at the plate surface. There was a retarding effect on the heat transfer rate as $\mathrm{Br}, \mathrm{Ra}$ and $\lambda$ were increased due to viscous dissipation.

Table 4. Computation of the values of the coefficient of skin-friction $f^{\prime \prime}(0), \mathrm{Gr}=0.1, \mathrm{Gr}=0.5$ and for various values of $F_{w}$ and $M$ with $\mathrm{Sc}=0.24, \quad n=1 \quad$ and $\quad \mathrm{Pr}=0.72, \quad \mathrm{Br}=\lambda=\mathrm{Bi}=0.1$.

\begin{tabular}{|c|c|c|c|c|}
\hline \multirow{2}{*}{$\mathrm{Br}$} & \multirow{2}{*}{$F_{w}$} & \multirow{2}{*}{$M$} & \multicolumn{2}{|c|}{$f^{\prime \prime}(0)$} \\
\hline & & & $\mathrm{Gr}=0.1$ & $\mathrm{Gr}=0.5$ \\
\hline \multirow[t]{2}{*}{0.1} & \multirow[t]{2}{*}{-0.5} & 0.1 & 0.39361058 & 0.65350847 \\
\hline & & 0.5 & 0.70067376 & 0.90802398 \\
\hline \multirow[t]{2}{*}{0.1} & \multirow[t]{2}{*}{-0.2} & 0.1 & 0.45707988 & 0.68141995 \\
\hline & & 0.5 & 0.76538977 & 0.94502622 \\
\hline \multirow[t]{2}{*}{0.1} & \multirow[t]{2}{*}{0.1} & 0.1 & 0.53696439 & 0.72717975 \\
\hline & & 0.5 & 0.83964894 & 0.99484111 \\
\hline \multirow[t]{2}{*}{0.1} & \multirow[t]{2}{*}{0.2} & 0.1 & 0.56665846 & 0.74636625 \\
\hline & & 0.5 & 0.86636772 & 1.01419416 \\
\hline \multirow[t]{2}{*}{0.1} & \multirow[t]{2}{*}{0.2} & 0.1 & 0.57990202 & 0.81777795 \\
\hline & & 0.5 & 0.88152265 & 1.09168253 \\
\hline
\end{tabular}


Table 5. Computation of the values of the rate of mass transfer $-\phi^{\prime}(0)$ with $n=1$ and $n=2$ for various values of $\mathrm{Sc}$ and $K$ with $\mathrm{Sc}=0.24, n=1, \mathrm{Pr}=0.72, \mathrm{Br}=\mathrm{Gr}=\lambda=\mathrm{Bi}=M=0.1$ and $F_{w}=0.2$.

\begin{tabular}{|l|l|l|l|}
\hline \multirow{2}{*}{ Sc } & \multicolumn{1}{|c|}{$K$} & \multicolumn{2}{c|}{$-\phi^{\prime}(0)$} \\
& \multicolumn{1}{|c|}{$n=1$} \\
\hline \multirow{2}{*}{0.24} & 0.2 & 0.306149262887398 & 0.282317722057957 \\
\cline { 2 - 4 } & 0.5 & 0.401474188901933 & 0.351677619285553 \\
\hline \multirow{2}{*}{0.62} & 0.2 & 0.480601350113419 & 0.439729402647025 \\
\cline { 2 - 4 } & 0.5 & 0.640594758401727 & 0.556682245239545 \\
\hline \multirow{2}{*}{2.64} & 0.2 & 1.00000022213442 & 0.902937070038939 \\
\cline { 2 - 4 } & 0.5 & 1.35242007039814 & 1.16094061749772 \\
\hline
\end{tabular}

Table 6. Computation of the values of the plate temperature $\theta(0)$ and Nusselt number $-\theta^{\prime}(0)$ for various values of $\mathrm{Pr}$, $\mathrm{Ra}, M, \lambda, F_{w}$ and $\mathrm{Bi}$ with $\mathrm{Sc}=0.24, n=1$ and $\mathrm{Br}=K=0.1$.

\begin{tabular}{|l|l|l|l|l|l|l|l|l|}
\hline $\operatorname{Pr}$ & $\mathrm{Ra}$ & $M$ & $\mathrm{Br}$ & $\lambda$ & $\mathrm{Bi}$ & $F_{w}$ & $\theta(0)$ & $-\theta^{\prime}(0)$ \\
\hline 0.72 & 0.1 & 0.1 & 0.1 & 0.01 & 0.1 & 0.2 & 0.294179000291035 & 0.0705820999708965 \\
\hline 0.72 & 0.1 & 0.1 & 0.1 & 0.01 & 0.1 & 0.2 & 0.197259784726029 & 0.0802740215273972 \\
\hline 0.72 & 0.1 & 0.1 & 0.1 & 0.01 & 0.1 & 0.2 & 0.105635594228629 & 0.0894364405771371 \\
\hline 0.72 & 0.2 & 0.1 & 0.1 & 0.01 & 0.1 & 0.2 & 0.298728417419719 & 0.0701271582580281 \\
\hline 0.72 & 0.5 & 0.1 & 0.1 & 0.01 & 0.1 & 0.2 & 0.311607584522124 & 0.0688392415477876 \\
\hline 0.72 & 0.7 & 0.1 & 0.1 & 0.01 & 0.1 & 0.2 & 0.319524516162399 & 0.0680475483837601 \\
\hline 0.72 & 0.1 & 0.5 & 0.1 & 0.01 & 0.1 & 0.2 & 0.334401846213312 & 0.0665598153786687 \\
\hline 0.72 & 0.1 & 1.5 & 0.1 & 0.01 & 0.1 & 0.2 & 0.401694171590128 & 0.0598305828409872 \\
\hline 0.72 & 0.1 & 2.0 & 0.1 & 0.01 & 0.1 & 0.2 & 0.427892749481842 & 0.0572107250518158 \\
\hline 0.72 & 0.1 & 0.1 & 0.2 & 0.01 & 0.1 & 0.2 & 0.361953891510507 & 0.0638046108489493 \\
\hline 0.72 & 0.1 & 0.1 & 0.5 & 0.01 & 0.1 & 0.2 & 0.573874654466193 & 0.0426125345533806 \\
\hline 0.72 & 0.1 & 0.1 & 0.8 & 0.01 & 0.1 & 0.2 & 0.800059046108015 & 0.0199940953891985 \\
\hline 0.72 & 0.1 & 0.1 & 0.1 & 0.02 & 0.1 & 0.2 & 0.299897798159221 & 0.0700102201840779 \\
\hline 0.72 & 0.1 & 0.1 & 0.1 & 0.05 & 0.1 & 0.2 & 0.318922669945282 & 0.0681077330054718 \\
\hline 0.72 & 0.1 & 0.1 & 0.1 & 0.09 & 0.1 & 0.2 & 0.349732052451735 & 0.0650267947548265 \\
\hline 0.72 & 0.1 & 0.1 & 0.1 & 0.01 & 0.2 & 0.2 & 0.424417014509244 & 0.115116597098151 \\
\hline 0.72 & 0.1 & 0.1 & 0.1 & 0.01 & 1.0 & 0.2 & 0.766077997636570 & 0.233922002363430 \\
\hline 0.72 & 0.1 & 0.1 & 0.1 & 0.01 & 2.0 & 0.2 & 0.865496405782359 & 0.269007188435282 \\
\hline
\end{tabular}

\section{A. Velocity profiles}

Figures 2 to 6 show the influence of some of the controlling parameters on the velocity boundary layer. The fluid velocity was lowered at the plate surface and increased to the free stream value satisfying the far field boundary condition. In Fig.2, the distractive force due to Lorentz force increased as the magnetic parameter increased because there was a very consistent drop in the longitudinal velocity and therefore the momentum boundary layer thickness get thinner. An increase in fluid injection, Grashof number and Brinkman number have the same effects on both the momentum boundary layer and velocity with the magnetic parameter as shown in Figs 3 to 6 . 


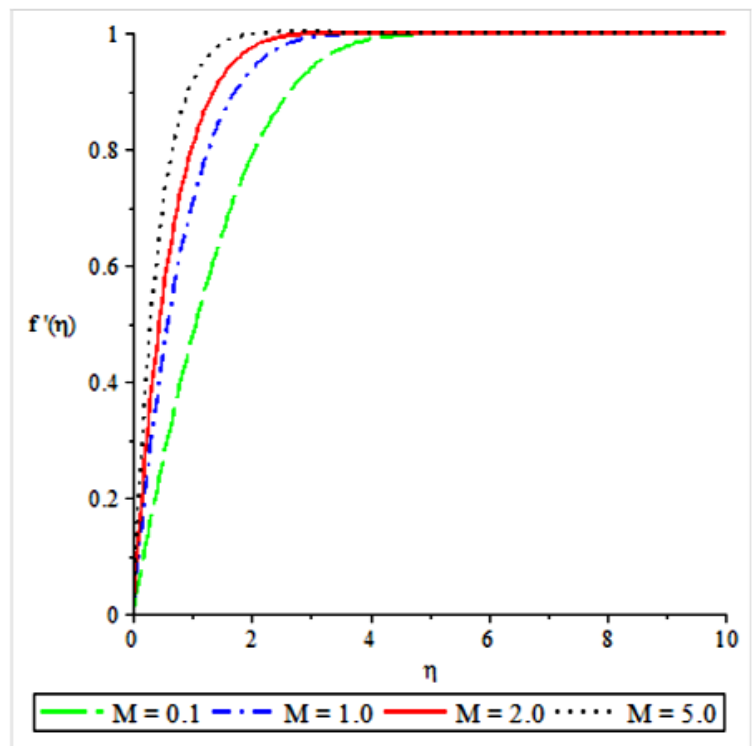

Fig.2. Velocity profiles for $\mathrm{Sc}=0.24, n=1, \operatorname{Pr}=0.72$, $\mathrm{Br}=\mathrm{Gr}=\mathrm{Ra}=\lambda=\mathrm{Bi}=K=0.1$ and $F_{w}=0.2$.

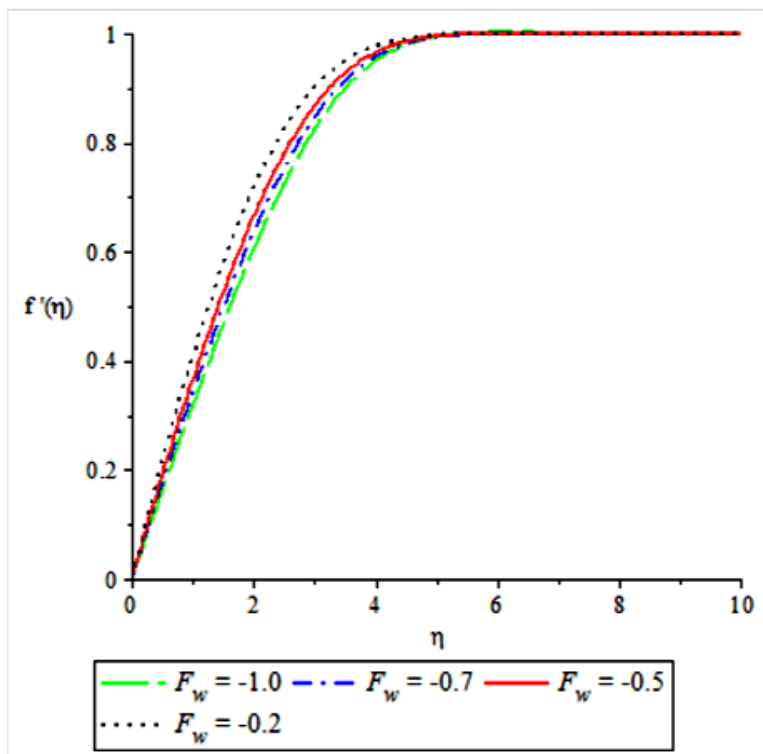

Fig.4. Velocity profiles for $\mathrm{Sc}=0.24, n=1, \mathrm{Pr}=0.72$ and $M=\mathrm{Br}=\mathrm{Gr}=\mathrm{Ra}=\lambda=\mathrm{Bi}=K=0.1$.

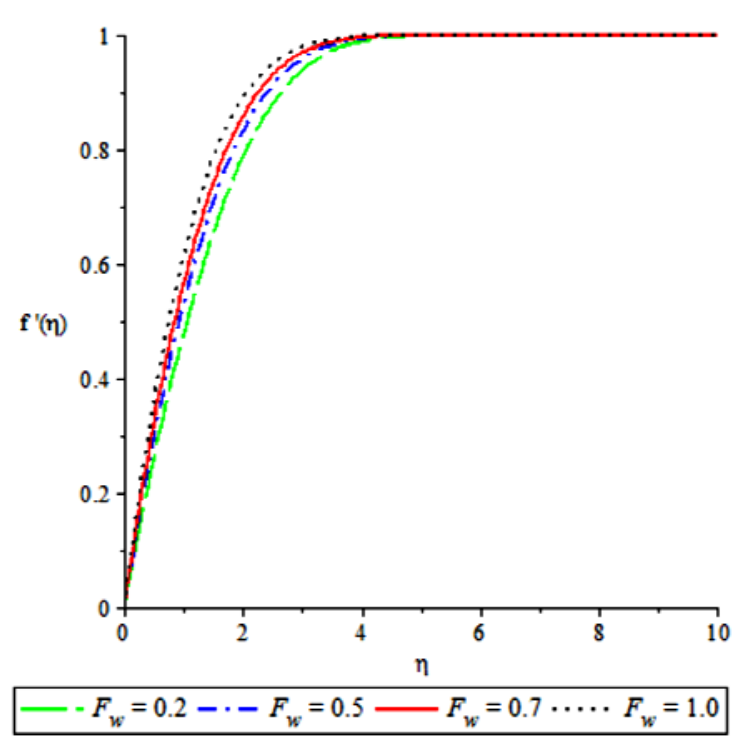

Fig.3. Velocity profiles for $\mathrm{Sc}=0.24, n=1, \operatorname{Pr}=0.72$ and $M=\mathrm{Br}=\mathrm{Gr}=\mathrm{Ra}=\lambda=\mathrm{Bi}=K=0.1$.

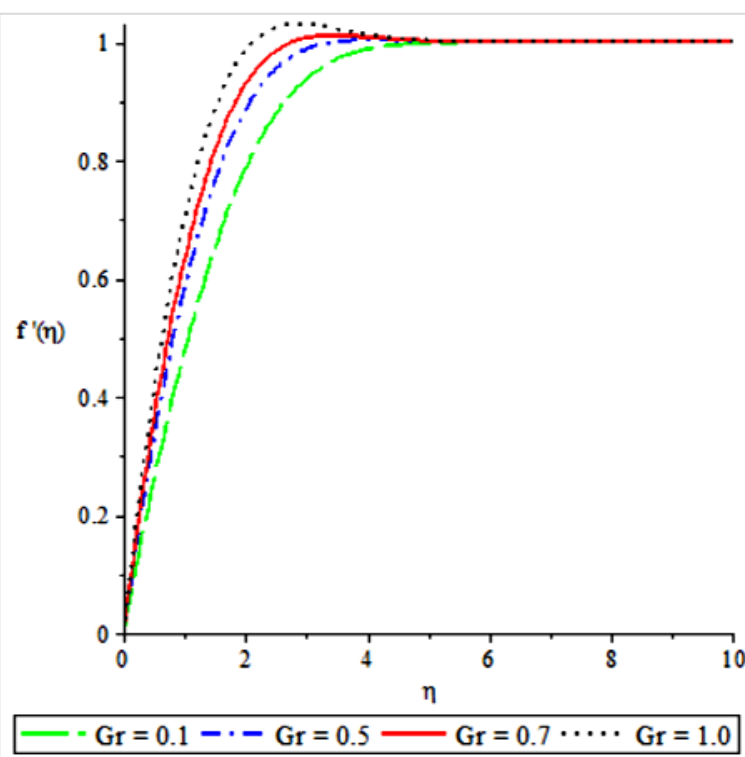

Fig.5. Velocity profiles for $\mathrm{Sc}=0.24, n=1, \mathrm{Pr}=0.72$, $\mathrm{Br}=M=\mathrm{Ra}=\lambda=\mathrm{Bi}=K=0.1$ and $F_{w}=0.2$. 


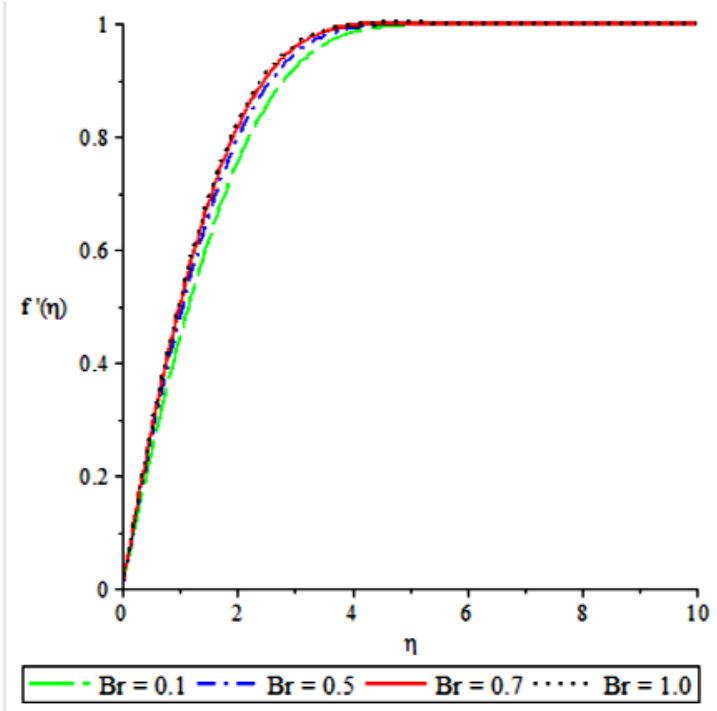

Fig.6. Velocity profiles for $\mathrm{Sc}=0.24, n=1, \mathrm{Pr}=0.72$ and $\mathrm{Gr}=M=\mathrm{Ra}=\lambda=\mathrm{Bi}=K=0.1$.

\section{B. Temperature profiles}

The effects of various controlling parameters on the temperature distribution are shown in Figs 7-14. It should be noted that, the temperature reaches its maximum at the permeable plate surface and asymptotically decreases to a minimum zero value far away from the plate, thereby satisfying the boundary condition. Also, increasing the magnetic parameter increases the fluid temperature which in turn increases the thermal boundary layer. This is attributed to the effect of Ohmic heating on the flow system. An increase in the Biot number gave rise to increase in fluid temperature due to the convective heat exchange between the hot fluid at the lower surface of the plate and the cold fluid at the upper surface of the plate resulting in the thickening of the thermal boundary layer. The same reason can be given for increase in the Brinkman number, internal heat generation parameter and radiation parameter but an opposite trend was observed by increasing the Prandtl number and fluid injection and so lowering the rate of thermal diffusion within the boundary layer resulting in a thinning of the thermal boundary layer.

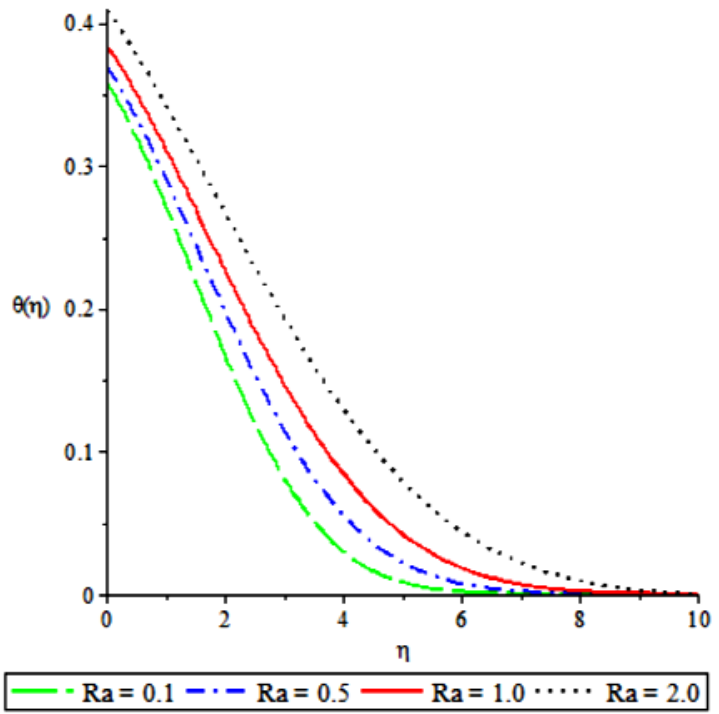

Fig.7. Temperature profiles $\mathrm{Sc}=0.24, n=1, \operatorname{Pr}=0.72$, $\mathrm{Br}=\mathrm{Gr}=M=\lambda=\mathrm{Bi}=K=0.1$ and $F_{w}=0.2$.

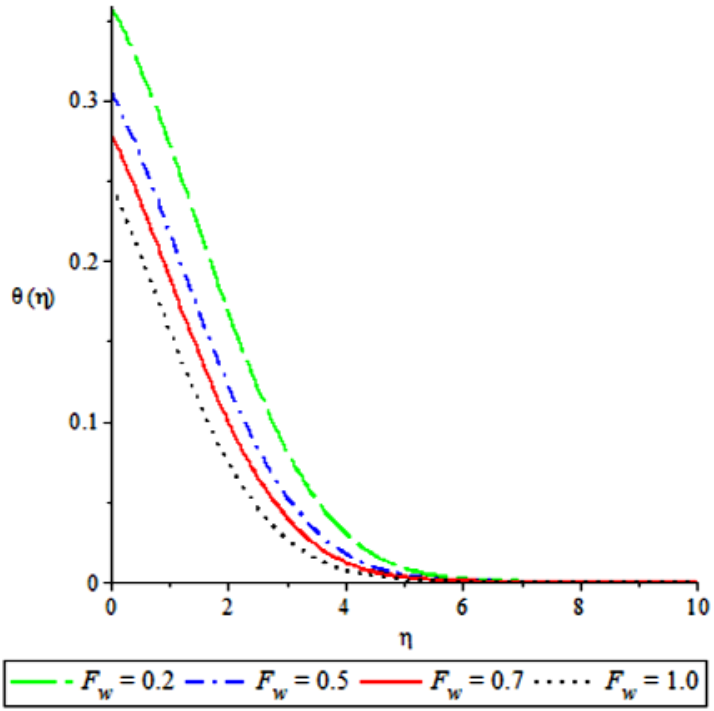

Fig.8. Temperature profiles for $\mathrm{Sc}=0.24, n=1, \mathrm{Pr}=0.72$ and $\mathrm{Br}=\mathrm{Gr}=M=\mathrm{Ra}=\lambda=\mathrm{Bi}=K=0.1$. 


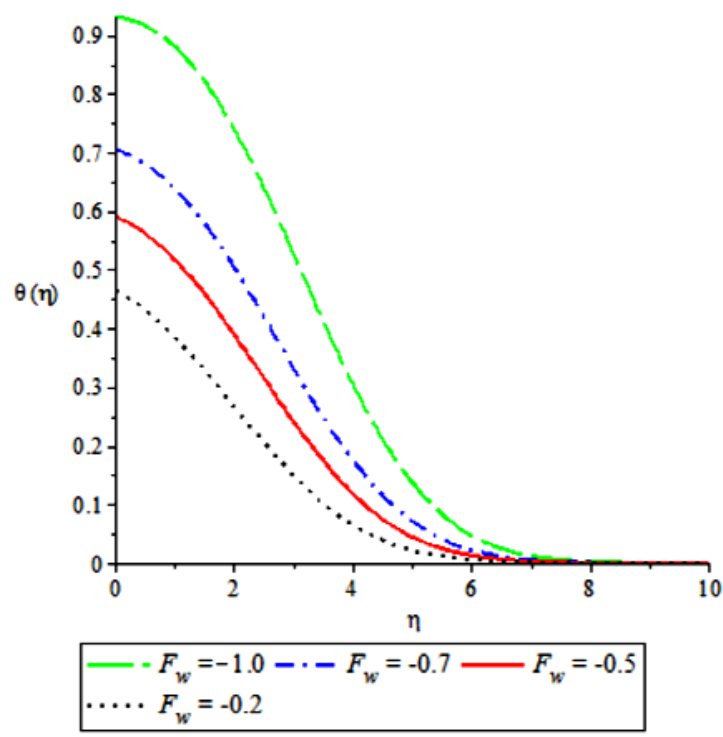

Fig.9. Temperature profiles for $\mathrm{Sc}=0.24, n=1, \mathrm{Pr}=0.72$, and $\mathrm{Br}=\mathrm{Gr}=M=\mathrm{Ra}=\lambda=\mathrm{Bi}=K=0$.

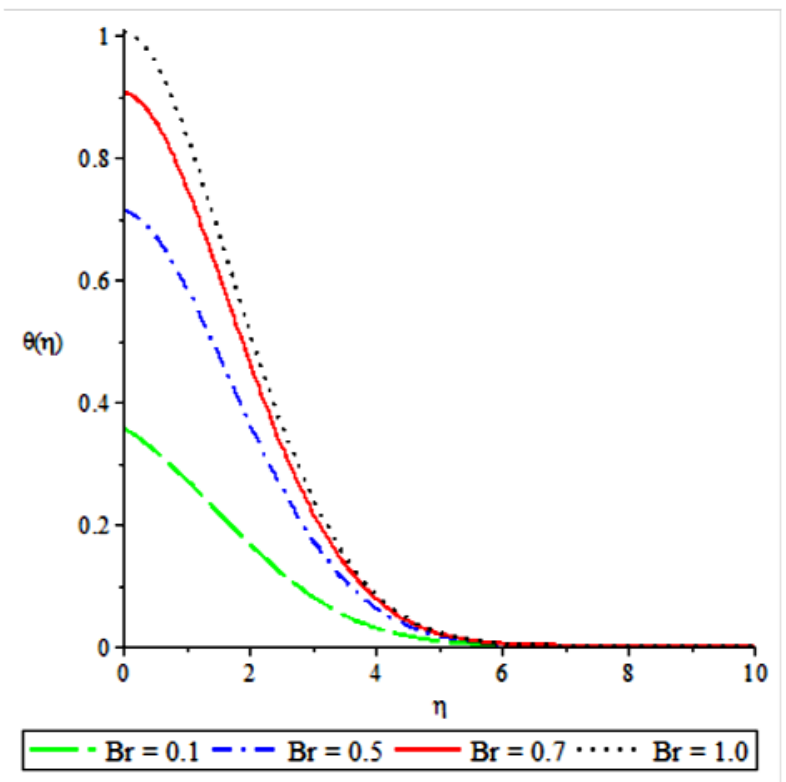

Fig.11. Temperature profiles for $\mathrm{Sc}=0.24, n=1, \mathrm{Pr}=0.72$, $\mathrm{Ra}=\mathrm{Gr}=M=\lambda=\mathrm{Bi}=K=0.1$ and $F_{w}=0.2$.

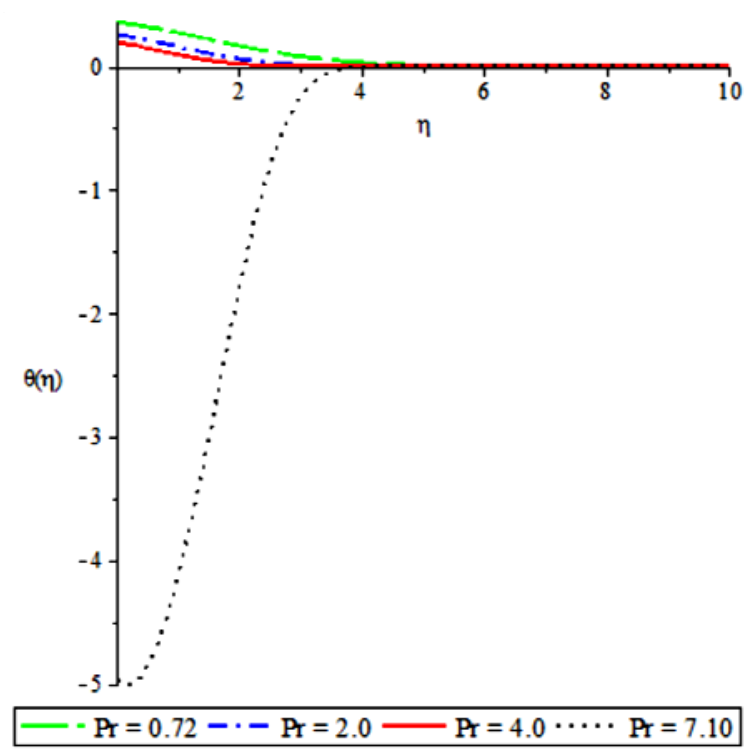

Fig.10. Temperature profiles for $\mathrm{Sc}=0.24, n=1$, $\mathrm{Ra}=\mathrm{Br}=\mathrm{Gr}=M=\lambda=\mathrm{Bi}=K=0.1$ and $F_{w}=0.2$.

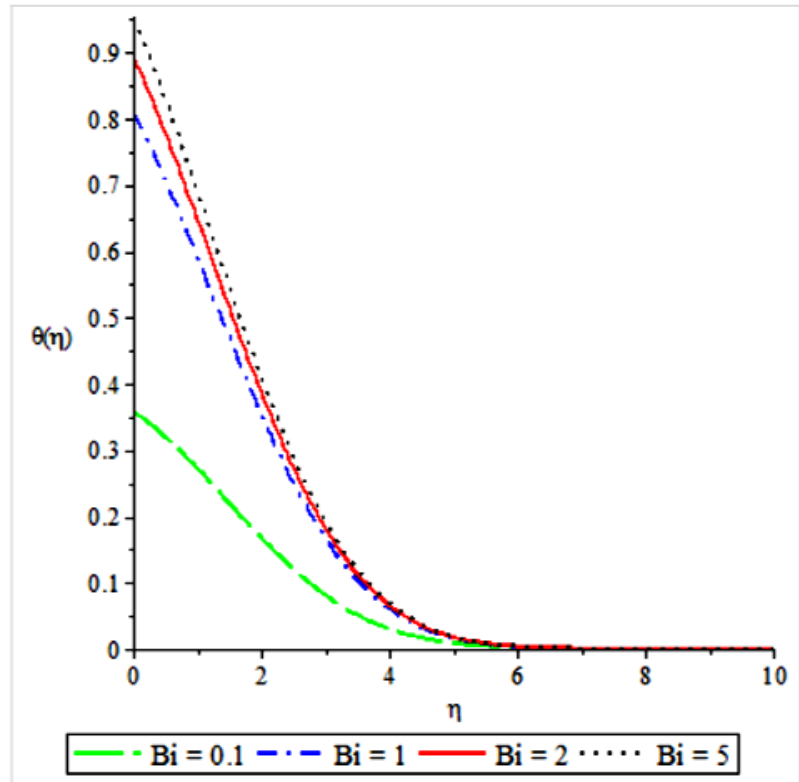

Fig.12. Temperature profiles for $\mathrm{Sc}=0.24, n=1, \mathrm{Pr}=0.72$, $\mathrm{Ra}=\mathrm{Br}=\mathrm{Gr}=M=\lambda=K=0.1$ and $F_{w}=0.2$. 


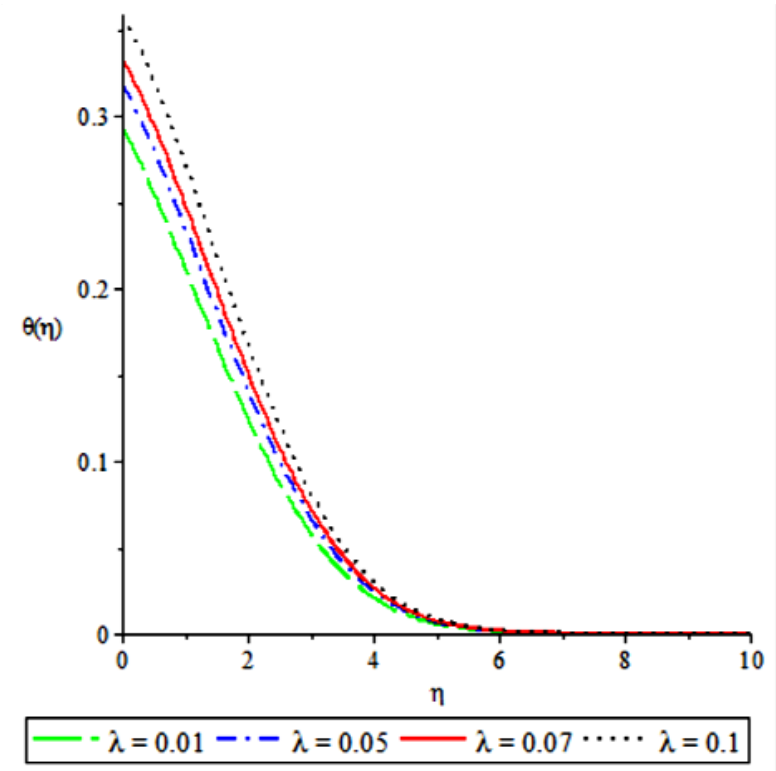

Fig.13. Temperature profiles for $\mathrm{Sc}=0.24, n=1$, $\operatorname{Pr}=0.72, \mathrm{Br}=\mathrm{Gr}=M=\mathrm{Ra}=\mathrm{Bi}=K=0.1$ and $F_{w}=0.2$.

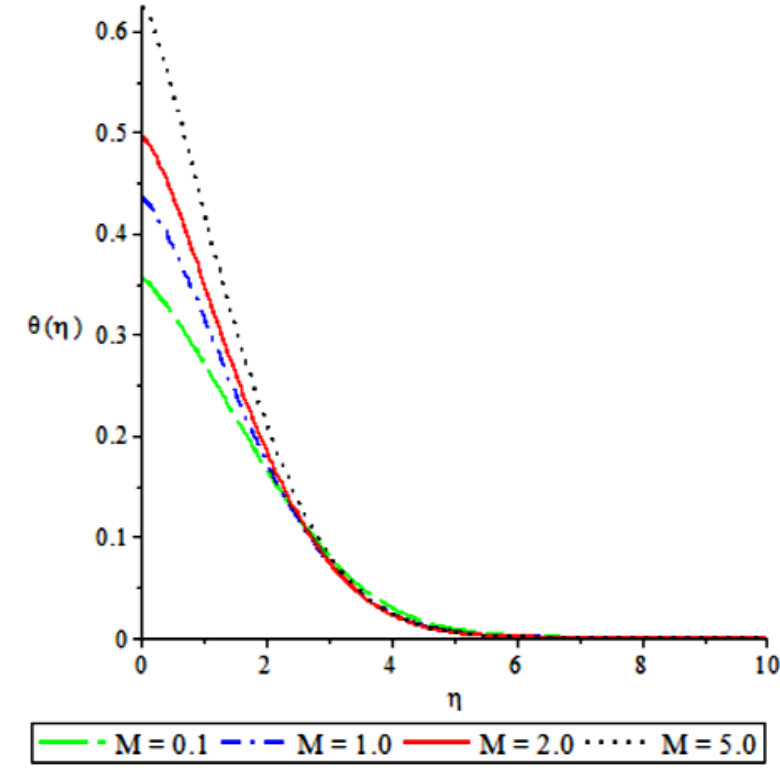

Fig.14. Temperature profiles for $\mathrm{Sc}=0.24, n=1$, $\operatorname{Pr}=0.72, \mathrm{Br}=\mathrm{Gr}=\lambda=\mathrm{Bi}=K=0.1$ and $F_{w}=0.2$.

\section{Concentration profiles}

The effects of the controlling parameters on concentration profile were shown in Figs 15-17. The boundary conditions were fulfilled as the graphs indicated maximum concentration at the permeable plate surface and asymptotical decrease to the prescribed free stream value. Fluid injection and suction, Schmidt number and the reaction rate parameters decreased the rate of mass diffusivity. The solutal boundary layer also decreased for all the three controlling parameters.

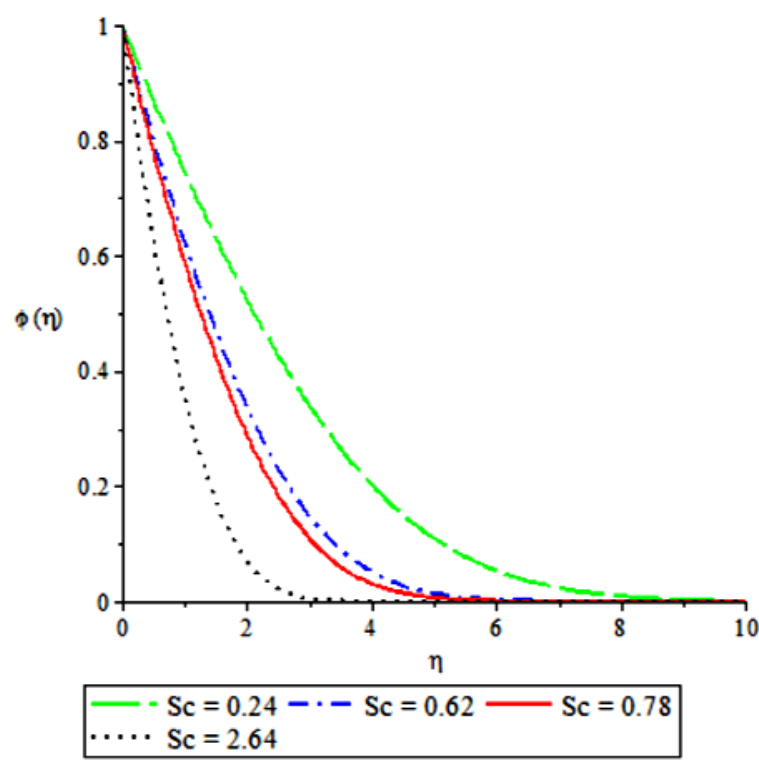

Fig.15. Concentration profiles for $n=1, \operatorname{Pr}=0.72$,

$\mathrm{Br}=\mathrm{Gr}=K=\lambda=\mathrm{Bi}=M=0.1$ and $F_{w}=0.2$.

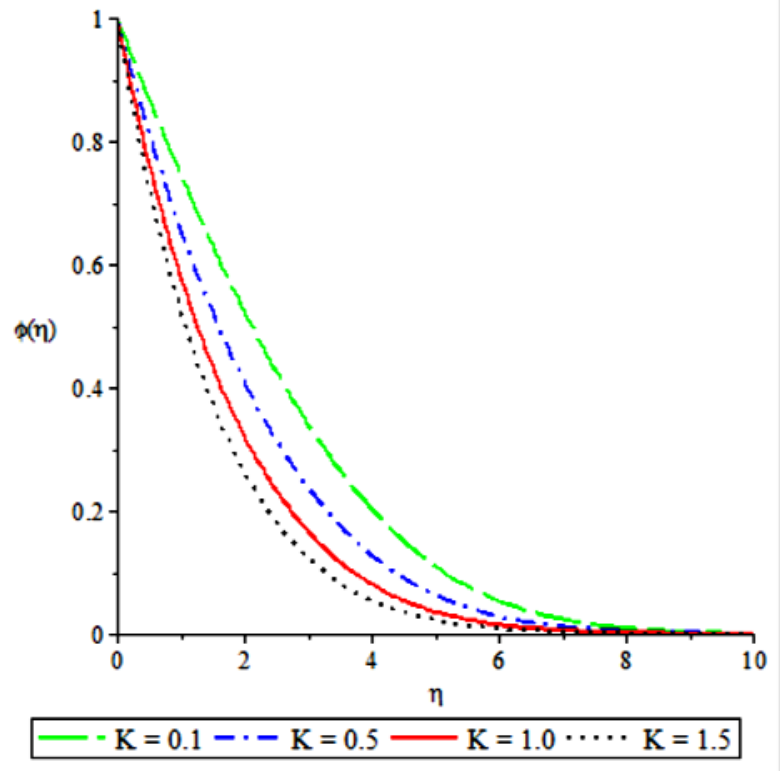

Fig.16. Concentration profiles for $\mathrm{Sc}=0.24, n=1$, $\operatorname{Pr}=0.72, \mathrm{Br}=\mathrm{Gr}=\lambda=\mathrm{Bi}=M=0.1$ and $F_{w}=0.2$. 


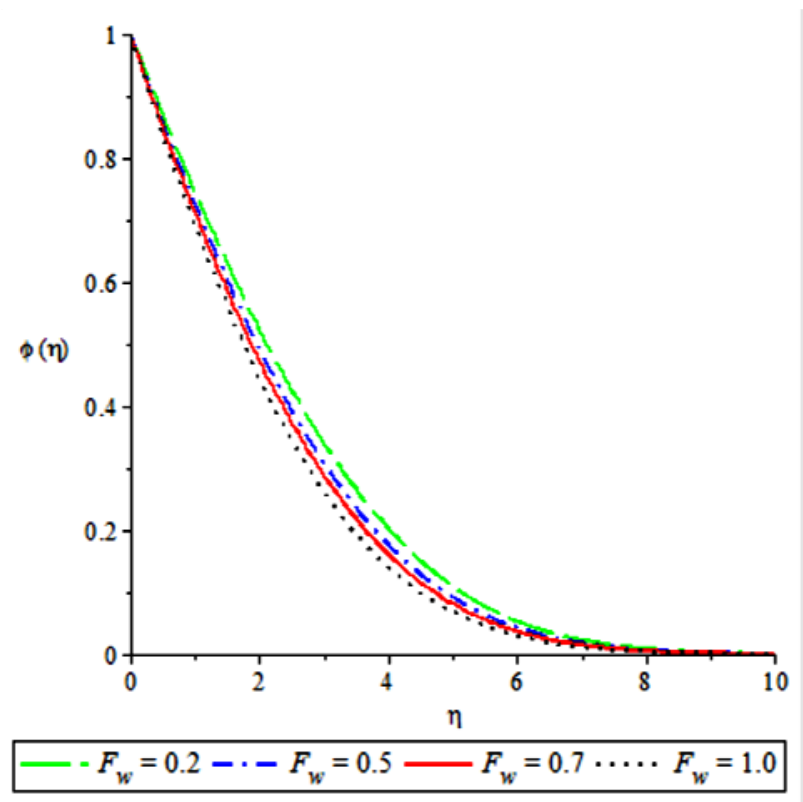

Fig.17. Concentration profiles for $\mathrm{Sc}=0.24, n=1, \mathrm{Pr}=0.72$ and $\mathrm{Br}=\mathrm{Gr}=\lambda=\mathrm{Bi}=M=K=0.1$.

Conclusively, this work examined the analysis of a steady, two-dimensional, chemically reactive MHD flow of heat and mass transfer of a viscous, incompressible, chemically reactive and electrically conducting fluid flow over a permeable surface. The similarity equations were obtained and solved numerically using Runge-Kutta method based on Shooting technique. Numerical results were presented, illustrated and analyzed graphically with all the controlling thermo physical parameters in the velocity, temperature and concentration profiles. Then, it was noted that:

- increase in radiation parameter, magnetic parameter, Brinkman number and internal heat generation parameter increase the plate surface temperature but decrease the rate of heat transfer.

- the plate temperature decreases with fluid suction/injection and increases with Prandtl number

- fluid suction/injection and Prandtl number increase the rate of heat transfer;

- all the embedded parameters in the momentum boundary layer equations increase the skin friction coefficient;

- there is a faster rate of mass movement when the reaction rate parameter and Schmidt number are increased;

- fluid suction/injection has significant effect on the Skin-friction coefficient, Nusselt number and Sherwood number;

- the order of the chemical reaction is quite significant;

- all the embedded parameters in the momentum boundary layer equations decrease the momentum boundary layer.

\section{Aknowledgement}

We appreciate the comments of the reviewers in improving the quality of the paper.

\section{Nomenclature}

Bi - Biot number

$\mathrm{Br}$ - Brinkman number

$B_{0}-$ uniform magnetic field or magnetic field strength $\left[\mathrm{Am}^{-1}\right]$

$C$ - specific concentration of the fluid inside the plate/boundary layer $\left[\mathrm{molm}^{-3}\right]$ 
$C_{f}-$ concentration from viscous fluid that give rise to coefficient mass transfer $\left[\mathrm{molm}^{-3}\right]$

$C_{\infty} \quad$ - specific concentration outside the plate/boundary layer $\left[\mathrm{molm}^{-3}\right]$

$c_{p}$ - specific heat at constant pressure $[\mathrm{J} / \mathrm{kgK}]$

$D_{m}$ - mass diffusivity

$F_{w}-$ suction/injection

$f^{\prime \prime}(0) \quad$ - skin friction coefficient

Gr - Grashof number

$g$ - acceleration due to gravity $\left[\mathrm{ms}^{-2}\right]$

$h_{f}-$ heat transfer coefficient $\left[\mathrm{Wm}^{3} \mathrm{~K}^{=1}\right]$

$K$ - mean absorption coefficient

$K$ - thermal conductivity coefficient $\left[\mathrm{Wm}^{-1} \mathrm{k}^{-1}\right]$

$K_{r}-$ reaction rate constant $[\mathrm{mol} . / \mathrm{s}]$

$M$ - magnetic parameter

MHD - magnetohydrodynamics

$n$ - order of the chemical reaction

Pr - Prandtl number

$R a$ - radiation parameter

$q_{r} \quad$ - radiative heat flux $\left[\mathrm{Wm}^{-2}\right]$

Sc - Schmidt number

$T$ - fluid temperature inside the plate/boundary layer $[K]$

$T_{f} \quad$ - hot fluid temperature $[K]$

$T_{\infty} \quad$ - fluid temperature outside the plate/boundary layer $[K]$

$U_{\infty}-$ velocity outside the plate or free stream velocity $\left[\mathrm{ms}^{-1}\right]$

$u$ and $v$ - velocity components along $x$ and $y\left[\mathrm{~ms}^{-1}\right]$

$x$ and $y$ - Cartesian coordinates $[m]$

$\beta-$ thermal expansion coefficient

$\gamma$ - coefficient of the kinematic viscosity

$-\theta^{\prime}(0) \quad$ - Nusselt number

$\lambda$ - internal heat generation parameter

$\rho-$ fluid density $\left[\mathrm{kgm}^{3}\right]$

$\sigma$ - electrical conductivity $\left[\mathrm{Sm}^{-1}\right]$

$\sigma^{*}-$ Stefan-Boltzman constant

$-\varphi^{\prime}(0) \quad-$ Sherwood number

$\psi-$ stream function $\left[\mathrm{m}^{2} \mathrm{~s}^{-1}\right]$

\section{References}

[1] Chamkha Ali J. (2011): Heat and Mass transfer from MHD flow over a moving permeable cylinder with heat generation or absorption and chemical reaction. - Communications in Numerical Analysis; vol.2011, doi:10.59/2011/cna-00109.

[2] Aziz A. (2009): Similarity solution for Laminar boundary layer over a flat plate with a convective surface boundary condition. - Communication of Nonlinear Science, Numerical Simulation, vol.14, pp.1064-1068. 
[3] Bhattacharyya K. and Gorla R.S.R. (2013): Boundary layer flow and heat transfer over a permeable shrinking cylinder with surface mass transfer. - International Journal of Applied Mehanics and Engineering, vol.18, No.4, pp.1003-1010.

[4] Bhattacharyya K. and Layek G.C. (2010): Chemically reactive solute distribution in MHD boundary layer flow over a permeable stretching sheet with suction or blowing. - Chemical Engineering Communication Group, LLC, Taylor and Francis, vol.197, pp.1527-1540.

[5] Bhattacharyya K. (2011): Effects of heat source/sink on MHD flow and heat transfer over a shrinking sheet with mass suction. - Chemical Engineering Research Bulletin, vol.15, pp.12-17.

[6] Arthur E.M., Seini I.Y. and Seidu A. (2014): On chemically reacting yydromagneticflow over a flat surface in the presence of radiation with viscous dissipation and convective boundary condition. -America journal of APPLIED Mathematics, vol.2, No.5, pp.179-185.

[7] Gnaneswara Reddy Machireddy and Sandeep Naramgari (2016): Heat and mass transfer in radiative MHD Carreau fluid with cross diffusion. - Ain Shams Engineering Journal, asej 2016.06.012.

[8] Nayak M.K. (2016): Steady MHD flow and heat transfer on a stretching vertical permeable surface in the presence of heat generation/absorption, thermal radiation and chemical reaction. - AMSE Journals, vol.85, No.1, pp.91-104.

[9] Prakash J., Durga Prasad P., Vinod Kumar G., Kirankumar R.V.M.S.S. and Varma S.V.K. (2016): Heat and mass transfer hydromagnetic radiative Casson fluid over an exponentially stretching sheet with source/sink. International Journal of Engineering Science Invension, vol.5, No.7, pp.12-23.

[10] Sulocchana C. and Kishor Kumar M.K. (2016): Numerical investigation of heat and mass transfer in radiativeMagnetohydrodynamic flow with chemical reaction. - International Journal of Advanced Science and Technology, vol.96, pp.25-36.

[11] Seth G.S., Sharma R. and Kumbhakar B. (2016): Heat and mass effects on steady MHD natural convection flow of a chemically reactive and radiating fluid through a porous medium past a moving vertical plate with arbitrary ramped temperature. - Journal of Applied fluid Mechanics, vol.9, No.1, pp.103-117.

[12] Tasawar Hayat, Madiha Rashid, Maria Imtiaz and Ahed Alsaedi (2015): Magnetohydrodynamic stretched flow of a nanofluid with power-law velocity and chemical reaction. AIP Advances 5, pp.117-121.

[13] Ishak A. (2010): Similarity solution for flow and heat transfer over a permeable surface with convective boundary conditions. - Applied Mathematics and Computation, vol.217, No.2, pp.837-842.

[14] Makinde O.D and Olanrewaju P.O. (2010): Buoyancy effecta of thermal boundary layer over a vertical plate with convective surface boundary condition. - Journal of Fluid Engineering, vol.132/044502-1.

[15] Olanrewaju P.O., Gbadeyan J.A., Hayat J.A. and Hendi A. (2011): Effects of heat generation, thermal radiation and buoyancy force on a boundary layer flow over a vertical plate with convective surface boundary condition. South Africa Journal of Science, vol.107(9/10).

[16] Conte S.D. and Boor C. (1981): Elementary Numerical Analysis. - New York: McGraw-Hill Book Co..

[17] Jain M.K. (1984): Numerical Solution of Differential Equations. - New Delhi, India: Wiley Eastern Ltd..

[18] Jain M.K., Iyengar S.R. and Jain R.K. (1985): Numerical Methods for Scientific and Engineering Computations. New Delhi, India: Wiley Eastern Limited.

[19] Krishnamurthy E.V. and Sen S.K. (1986): Numerical Algorithms. - New Delhi, India: Affiliated East-West Press Pvt. Ltd..

[20] Heck A. (2003): Introduction to Maple. - 3rd Edition, Springer-Verlag. 